\title{
ANÁLISE DAS CONDIÇÕES ERGONÔMICAS E AMBIENTAIS EM POSTOS DE TRABALHO DE MOTORISTAS DE CAMINHÕES UTILIZADOS NO MEIO RURAL E AGROINDUSTRIAL
}

\author{
Lissara Polano Ody ${ }^{1}$, Alex Leal de Oliveira ${ }^{1}$, Lauren Morais da Silva ${ }^{1}$ \\ ${ }^{I}$ Departamento de Engenharia Rural, Universidade Federal do Pampa, 97546-550, Alegrete, Brasil.
}

*E-mail: lissaraody@yahoo.com.br

Recebido em: 26/03/2019 Aceito em: 08/01/2020

\section{RESUMO}

O transporte de cargas que move a economia do Brasil é conduzido com soberania através do sistema rodoviário, sobrelevando o motorista de caminhão a uma profissão de enorme importância para os diversos segmentos econômicos, em especial, para o agronegócio. O objetivo do presente trabalho foi avaliar as condições ergonômicas e ambientais dos postos de trabalho de motoristas de caminhão que atuam em atividades vinculadas ao agronegócio. O estudo de caso foi realizado na Fronteira Oeste com motoristas profissionais que executam tarefas no meio rural e agroindustrial. Para análise postural, executou-se filmagens e a geração de 240 fotos sequenciais como referencial do ciclo de atividade. Através do Software Ergolândia 6.0 as imagens foram analisadas pelo método RULA, que resultou na necessidade de intervenção na postura dos motoristas. Por meio do Questionário Bipolar foi observado que a atividade exercida pelos motoristas apresenta um quadro doloroso. Em relação as análises de ruído ocupacional e temperatura, nenhum parâmetro apresentou conforto aos indivíduos conforme a normalização da NR 17. Os valores de iluminação mostraram-se bastante deficientes devida à falta de uma norma específica para o interior da cabine de caminhões.

Palavras-chave: Agronegócio. Transporte. Caminhão. Saúde Ocupacional.

\section{Introdução}

O Brasil está entre os países que mais opera a malha rodoviária para o escoamento de grãos, frutas, produtos agroindustrializados em geral, além do transporte de cargas. O país é tradicionalmente associado à agricultura por sua diversidade de plantas cultivadas, solos férteis e vastidão do território nacional, caracterizando-se em uma potência exportadora de commodities agrícolas.

Em um cenário de intensa concorrência nos mercados, a logística tem como atribuição responder por todas as movimentações de mercadorias, da expedição até a entrega ao destino final, tornando-se uma atividade cada vez mais expressiva no contexto atual [1]. No agronegócio, a logística relaciona-se ao planejamento e operação dos sistemas físicos, informacionais e gerenciais, necessários para que insumos e produtos se movimentem de forma integrada no espaço, através do transporte no momento certo, para o lugar certo e com o menor custo possível [2].

Muitos produtores rurais antecipam o contrato de prestação de serviços com caminhões, por terem receio da insuficiência ou falta de veículos nas épocas de maior demanda logística, a exemplo dos períodos de retirada de grãos na colheita e posterior deslocamento para as Unidades de Beneficiamento de Grãos, entrepostos de recebimento e portos. Esta real necessidade do modal rodoviário, evidência a importância da profissão do caminhoneiro para a economia do país, pois participam diretamente dos processos logísticos relacionados às atividades agrícolas.

O motorista está sujeito a diversas condições de trabalho e ambiente que podem influenciar na sua segurança, saúde e qualidade de vida. De acordo com Ribeiro [3], os motoristas são expostos a condições questionáveis de temperatura, ruído e ergonomia, pois os mesmos permanecem por muito tempo sentados devido às longas viagens.

Lima e Siqueira [4], ressaltam ainda, que os motoristas deste transporte sofrem pressão e suscetibilidade ao desenvolvimento de problemas emocionais e psicológicos, em virtude de uma rotina de deslocamento contínuo e repetitivo em um ambiente de trabalho hostil (vias e tráfego) e com mínimo espaço no posto de trabalho (cabine).

A exposição ao ruído, calor e permanência em uma mesma posição frente ao volante, demandam a esses profissionais uma intensa concentração física e mental, vindo a comprometer sua saúde em geral [5]. 
Logo, ações direcionadas para esse público deveriam demandar maior atenção por parte dos gestores de operação logística e de produção, pois nem sempre o estudo das condições de trabalho desses profissionais é conceituado e explorado como deveria.

Neste contexto, o objetivo do presente trabalho foi avaliar as condições ergonômicas e ambientais dos postos de trabalho de motoristas de caminhão que atuam em atividades vinculadas ao agronegócio.

\section{Metodologia}

\subsection{Localização e caracterização do estudo}

O estudo de caso foi realizado na região da Fronteira Oeste do Rio Grande do Sul, especificamente nas imediações rurais. As atividades foram iniciadas em março de 2018, com uma ampla revisão bibliográfica sobre o tema, planejamento das estratégias de coleta de dados e posterior atividade de campo. As referidas coletas, ocorreram a campo, durante o mês de Setembro de 2018. Foram avaliados três motoristas profissionais de caminhão, em diferentes faixas etárias, todos do sexo masculino. Esta análise ocorreu em distintos modelos de caminhão. O referencial amostral escolhido permite caracterizar e explicar as diferenças e semelhanças entre os indivíduos do estudo, como também, os indivíduos de validade externa. Com o objetivo de caracterizar o referencial amostral dos motoristas, foi elaborada a Tabela 1, que demonstra os perfis de cada um dos respondentes.

Tabela 1 - Perfil do respondente.

\begin{tabular}{cl}
\hline Respondentes & \multicolumn{1}{c}{ Caracterização } \\
\hline \multirow{3}{*}{ A } & $\begin{array}{l}\text { Sexo masculino, 63 anos, motorista profissional há 44 anos, } \\
\text { trajeto habitual (Uruguaiana-RS à Barra do Quaraí-RS), } \\
\text { executa o transporte de arroz em casca a granel, não interage } \\
\text { de vícios nem utiliza medicamentos. }\end{array}$ \\
\hline & $\begin{array}{l}\text { Sexo masculino, 76 anos, motorista profissional há 50 anos, } \\
\text { trajeto habitual (zonas rurais de Alegrete - RS), transporta } \\
\text { máquinas e implementos agrícolas, apresenta doença } \\
\text { crônica como Hipertensão Arterial, e faz uso de } \\
\text { medicamentos. Não possui nenhum vício com substâncias }\end{array}$ \\
& psicoativas. \\
\hline C & $\begin{array}{l}\text { Sexo masculino, 42 anos, motorista profissional há 18 anos, } \\
\text { trajeto habitual indefinido (na Região do Mercosul), executa } \\
\text { carregamento de peças agrícolas, fumante eventual, possui }\end{array}$ \\
& Hipertensão Arterial, e realiza o uso de medicamentos. \\
\hline
\end{tabular}

Os veículos investigados apresentam particularidades em relação aos dados técnicos. A Tabela 2 fornece algumas descrições dos caminhões em questão.
No que se refere as análises posturais, foram utilizadas duas técnicas, sendo essas: inspeção visual e filmagens do ciclo da atividade. A observação foi realizada, buscando enfatizar o movimento e comportamento mais frequente ao longo da jornada de trabalho. Para a realização desta etapa da análise, foi fixada uma câmera GoPro na parte interna da cabine do caminhão, com ângulo projetado ao plano de trabalho do caminhoneiro, de modo a registrar o posicionamento de membros superiores e inferiores do trabalhador.

Tabela 2 - Descrição dos veículos.

\begin{tabular}{|c|c|c|}
\hline Veículo & & \\
\hline \multirow{6}{*}{ A } & CABINE & CARROCERIA \\
\hline & Marca Scania & Marca Rondon \\
\hline & Modelo L110 & Graneleira: 3 eixos \\
\hline & 4×2 "Jacaré" & Dimensões: \\
\hline & 10 marchas & $12,40 \mathrm{~m} \times 1,60 \mathrm{~m}$ \\
\hline & Ano 1976 & \\
\hline \multirow{5}{*}{ B } & CAMINHÃO & \\
\hline & Marca Mercedes & \\
\hline & Modelo LP321 & TRUCADO \\
\hline & 5 marchas & \\
\hline & Ano 1964 & \\
\hline \multirow{6}{*}{$\mathrm{C}$} & CABINE & CARROCERIA \\
\hline & Marca Volvo & Marca Rondon \\
\hline & Modelo FH380 & Modelo Sider \\
\hline & $6 \times 2 \mathrm{~T}$ Balancim & 3 eixos \\
\hline & 16 marchas & Dimensões: \\
\hline & Ano 2002 & $15 \mathrm{~m} \times 2,55$ \\
\hline
\end{tabular}

A análise postural foi efetuada empregando o método RULA, através do software Ergolândia 6.0. O método RULA foi utilizado a partir da observação dos membros superiores (braços, antebraços e punhos) e inferiores (pescoço, tronco, pernas e pé), em situação de trabalho durante o tempo necessário para realização da tarefa.

Durante a aplicação do método RULA, cada fator recebe uma pontuação de acordo com a postura empregada, baseada nas relações das angulações entre os membros e o corpo, de forma que fossem compreendidas entre: 0 pontos, que representa a postura com menor risco de lesão e 4 pontos, que representa a postura com maior risco de lesão para o segmento corporal avaliado, conforme descrição do método na Tabela 3.

Durante a jornada de trabalho, foi aplicado o método do Questionário Bipolar, por meio de uma entrevista pessoal, no qual pretendeu-se avaliar em quais partes do corpo dos motoristas profissionais tinham maior possibilidade de lesão ou dor e em quais momentos o trabalhador sentia maior desconforto durante a sua atividade laboral. O respondente informou a frequência de dores, a posição do lado (esquerdo e/ou direito) e a sensação dos incômodos durante as horas trabalhadas. 
Tabela 3 - Pontuação geral do nível de intervenção ergonômica método RULA.

\begin{tabular}{ccl}
\hline Pontuação & Nível de Ação & \multicolumn{1}{c}{ Intervenção } \\
\hline 1 ou 2 & 1 & Postura aceitável \\
\hline 3 ou 4 & 2 & $\begin{array}{l}\text { Deve-se realizar uma observação. } \\
\text { Pode ser necessárias mudanças. }\end{array}$ \\
\hline 5 ou 6 & 3 & $\begin{array}{l}\text { Deve-se realizar uma investigação. } \\
\text { Devem ser introduzidas mudanças. }\end{array}$ \\
\hline 7 & 4 & $\begin{array}{l}\text { Devem ser introduzidas mudanças } \\
\text { imediatamente. }\end{array}$ \\
\hline
\end{tabular}

O nível de ruído emitido pelo caminhão e percebido por seu condutor foi mensurado por Medidor de Nível de Pressão Sonora (decibelímetro) devidamente certificado e calibrado, sendo que os pontos de análise foram tomados em duas condições: com vidros abertos e com vidros fechados, sendo as leituras realizadas na condição de veículo em movimento, com o instrumento de medição devidamente calibrado e certificado com posicionamento próximo a zona auditiva do motorista.

As medições de temperatura foram realizadas na altura do corpo mais atingida pelas condições ambientais, conforme estabelece a NR 15. Para isso, foi utilizado um termohigrômetro devidamente calibrado e certificado. As leituras da temperatura foram iniciadas após a estabilização térmica, e repetidas a cada 5 minutos de intervalo.

Para medição de iluminância foi utilizado um luxímetro digital com fotocélula corrigida para o olho humano, sendo que este equipamento foi projetado em diferentes planos de visão: plano frontal e plano lateral. A célula fotoelétrica do luxímetro foi posicionada ao nível dos olhos do trabalhador, orientando para os diversos planos, tomando cuidado adicional para que não projetasse sombra durante as medições.

\section{Resultados e discussões}

\subsection{Análise da Postura}

Para avaliação postural dos caminhoneiros foi considerada a totalidade de imagens analisadas, ou seja, 240 posturas. Aplicando ao método RULA, os resultados mostram que nenhuma postura assumida na atividade investigada obteve nível de ação 1 ou 2, sendo assim, não houve nenhum escore postural que fosse plenamente aceitável ao decorrer do ciclo de atividade. Durante a avaliação ergonômica, mais de $80 \%$ dos registros apresentaram resultados que mereciam investigação na postura, ou seja, nível de ação 3. A Tabela 4, demonstra a amplitude de movimentos e a pontuação gerada como escore final para a postura dos motoristas avaliados.
Na Tabela 4, é destacado que, alguns ângulos representam má postura dos motoristas ao dirigir. Por exemplo, a flexão do pescoço está entre $10^{\circ}$ e $20^{\circ}$, ocorrendo um pequeno curvamento, bem como, o tronco que apresentou inclinação para frente com angulação de $0^{\circ}-20^{\circ}$. Essas posturas inadequadas são comuns quando se passa muito tempo sentado, por isso, é importante ações educativas em saúde, para alcançarem mudanças ergonômicas.

Com base na intervenção encontrada para o ciclo de atividade de um caminhoneiro, é possível analisar algumas mudanças que podem serem introduzidas durante a jornada de trabalho. É importante aplicar um método de avaliação de risco ergonômico que seja mais adequado à realidade de trabalho a ser avaliado e que apresente uma orientação a gestão eficaz da saúde ocupacional. Para que, através da graduação hierárquica dos fatores de risco, seja facilitada a tomada de decisão para adoção de medidas corretivas.

Segundo Cars [6], sentar de forma adequada em frente ao volante de um caminhão pode salvar vidas, inclusive a do motorista desse tipo de veículo. Por isso, a atenção ao posicionamento adequado do corpo do condutor enquanto dirige é tão indispensável, tanto para sua segurança como para sua saúde.

Tabela 4 - Resultados encontrados para a análise postural (Método RULA).

\begin{tabular}{llcc}
\hline Descrição & Amplitude Movimento & Pontuação & Ação \\
\hline Braço & Flexão $20^{\circ}-45^{\circ}$ & 2 & \\
Antebraço & Flexão $60^{\circ}-100^{\circ}$ & 1 & 3 \\
Punho & Flexão e extensão $0^{\circ}-15^{\circ}$ & 2 & \\
\hline Pescoço & Flexão $10^{\circ}-20^{\circ}$ & 2 \\
Tronco & Deslocamento $0^{\circ}-20^{\circ}$ & 2 & 3 \\
Pernas & Apoiados e equilibrados & 1 & \\
Força & Menor do que $2 \mathrm{~kg}$ & 0 & \\
\hline
\end{tabular}

\subsection{Análise de dores e incômodos}

Após a aplicação do Questionário Bipolar, é possível observar que as partes mais críticas do corpo dos trabalhadores avaliados, foram as da região da cabeça (olhos, cabeça e pescoço) e dos membros do tronco (ombro, lombar e nádega). Diante disso, serão focadas análises e discussões acerca destas partes do corpo.

A amostra estudada apresenta que $100 \%$ dos trabalhadores sentem dor na lombar, cabeça e pescoço; $66,6 \%$ nos olhos e 33,3\% na nádega. Os indivíduos classificaram a evolução da dor na região lombar, pescoço e cabeça na primeira hora exercida de atividade como pequena (2) ou moderada (3), e na quarta e oitava hora trabalhada como severa (4), como pode ser analisado na Figura 1. 
Observa-se também que, ao decorrer das horas, ocorre a evolução gradual da dor, isto porque, o cansaço e fadiga refletem inevitavelmente nos trabalhadores.

Este estudo também identificou as regiões corporais mais frequentemente lesadas. Em relação a este parâmetro, os profissionais indicaram que sentem dor na região lombar durante todo o dia (5). Na cabeça, pescoço e nádega apontam que as lesões aparecem diversas vezes por dia (4). A sensação de desconforto nos olhos ocorre pelo menos cerca 1 vez por dia (3), os dados descritos podem ser vistos na Figura 2.

$\mathrm{Na}$ literatura consultada, verificou-se que há diversos fatores que podem ocasionar a sensação de incômodo nas regiões apontadas pelos motoristas durante o trabalho.

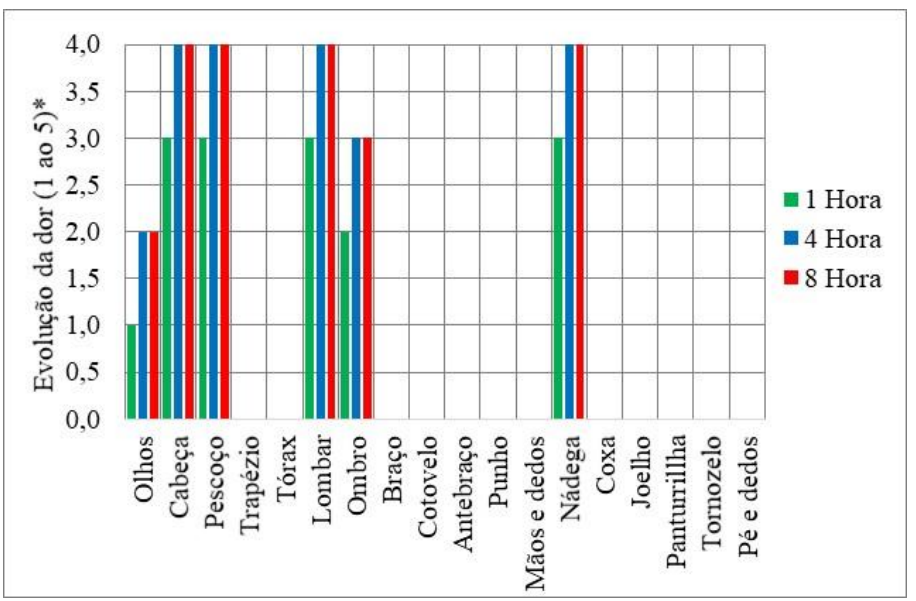

*Evolução da dor: (1) Ausente; (2) Pequeno; (3) Moderado; (4) Severo; (5) Insuportável.

Figura 1 - Evolução da dor durante as horas trabalhadas analisadas pelo Software Ergolândia.

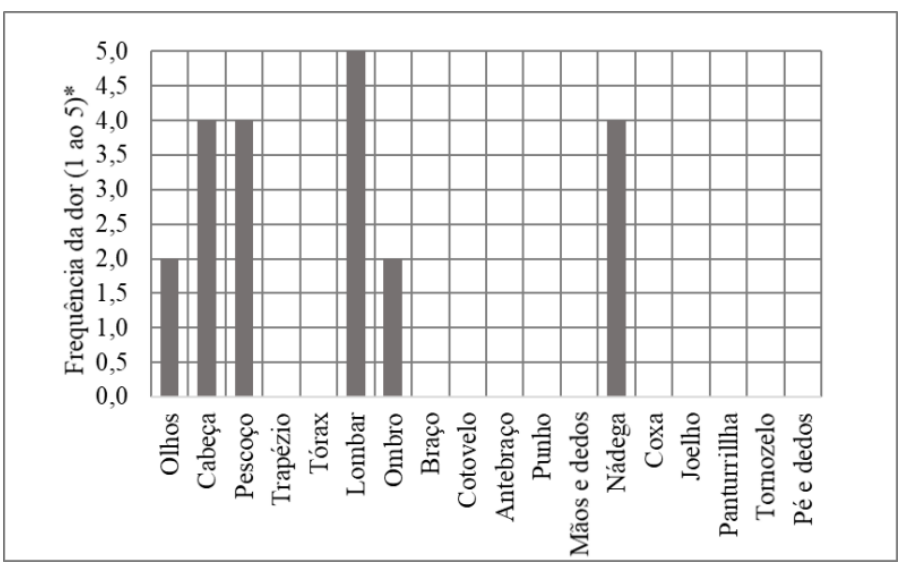

*Frequência da dor: (1) De 1 a 2 vezes por semana; (2) De 3 a 4 vezes por semana; (3) Cerca de 1 vez por dia; (4) Muitas vezes por dia; (5) Todo o dia (dia inteiro).

Figura 2 - Frequência da dor nas regiões do corpo pelo Software Ergolândia.
Uma das principais causas de afastamento temporário e permanente do trabalho no Brasil, é a lombalgia (dor na região lombar), que atinge mais da metade dos motoristas de caminhão, principalmente os que exercem a atividade várias horas por dia.

A posição conduzindo um caminhão, predispõe a projeção da cabeça e pescoço para frente e essa condição causa um estresse nos músculos. Além disso, a má postura corporal, longas horas na direção e esforço desproporcional, podem provocar tensões posturais dos ligamentos e acarretar desconfortos na região da cabeça.

A fadiga ocular indicada pelos profissionais, pode estar relacionada com as longas horas dirigindo com atenção, que estimulam os indivíduos a forçar a visão, o que acaba causando desconforto nos olhos.

Diante dos resultados observados, é visto que a atividade exercida pelos motoristas profissionais propicia um quadro doloroso. Portanto, faz-se necessário adotar um programa de prevenção, a fim de reduzir a fadiga muscular ocasionado pela atividade laboral, os riscos à saúde e desgaste de estruturas articulares e musculares, que resultam na sintomatologia dolorosa.

\subsection{Análise de variáveis ambientais}

As variáveis ambientais presentes nos postos de trabalho devem ser as mais agradáveis possíveis, a fim de proporcionar o melhor relacionamento entre o empregado e o seu posto de trabalho. Pois, quando desfavoráveis, podem provocar exaustão, extenuação física e nervosa, resultando no decréscimo do rendimento e qualidade do trabalho [7].

\subsubsection{Ruído Ocupacional}

A Tabela 5, apresenta a situação quanto ao nível de exposição ao ruído do motorista profissional quando em seu respectivo posto de trabalho em diferentes condições, sendo as leituras realizadas na condição de veículo em movimento. 


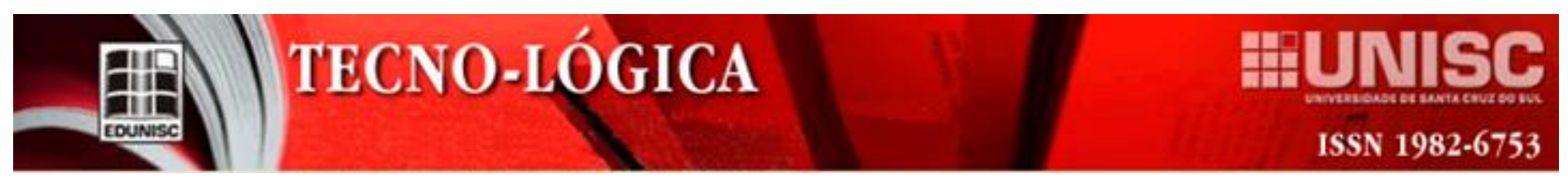

Tabela 5 - Medições do ruído no ambiente de trabalho.

\begin{tabular}{cccc} 
Tabela 5 - Medições do ruído no ambiente de trabalho. & & \\
\hline Ruído Ocupacional (dB) & $\mathbf{A}$ & $\mathbf{B}$ & $\mathbf{C}$ \\
\hline Condição I: Vidro Aberto & 85,0 & 88,3 & 71,1 \\
& 82,4 & 89,4 & 72,9 \\
Média & 81,4 & 86,8 & 72,4 \\
& 83,7 & 88,2 & 73,0 \\
\hline Condição II: Vidro Fechado & $\mathbf{8 3 , 1 3}$ & $\mathbf{8 8 , 1 8}$ & $\mathbf{7 2 , 3 5}$ \\
\hline & 79,1 & 83,3 & 66,8 \\
& 75,2 & 84,9 & 67,4 \\
& 80,7 & 85,4 & 68,5 \\
\hline Média & 77,9 & 83,8 & 68,8 \\
\hline
\end{tabular}

A Norma Regulamentadora 17 prevê no subitem 17.5.2.1 que para as atividades que exijam solicitação intelectual e atenção constante, o nível de ruído adequado para efeito de conforto é de até $65 \mathrm{~dB}$. Ao comparar os valores nas distintas condições com a NR 17 [8], foi observado que nenhuma situação está no nível de conforto acústico. O mais próximo da especificação aceitável é o caminhão $\mathrm{C}$ na condição de vidro fechado.

A NR 15 [9] assegura que atividades acima do limite de tolerância previstos na $\mathrm{NR} \mathrm{17,} \mathrm{mas} \mathrm{até} 85 \mathrm{~dB}$, não causam perturbação ou danos à saúde do trabalhador. Neste contexto, o caminhão B se encontra próximo/acima do valor de $85 \mathrm{~dB}$, limite tolerável até 8 horas de trabalho. Se o motorista trabalhasse continuamente 8 horas, sem a ocorrência de pausas durante o ciclo, este nível de ruído poderia causar lesão ao ouvido, podendo acarretar em prejuízo da função auditiva.

\subsubsection{Temperatura}

Como forma de comparação das condições de conforto interno nas cabines, foi necessário identificar as temperaturas externas no dia das coletas. Esses dados foram fornecidos pelo INMET - Instituto Nacional de Meteorologia, por intermédio de estações automáticas alocadas na região. A Tabela 6, apresenta a situação do posto de trabalho quanto ao índice de temperatura interna nos caminhões (dado mensurado na pesquisa) e estimativa da temperatura externa (dado fornecido).
Tabela 6 - Medições da temperatura no posto de trabalho.

\begin{tabular}{cccc}
\hline Temperatura $\left({ }^{\circ} \mathbf{C}\right)$ & $\mathbf{A}$ & $\mathbf{B}$ & $\mathbf{C}$ \\
\hline Temperatura Interna & 26,2 & 28,5 & 30,0 \\
& 27,0 & 28,1 & 30,0 \\
& 28,0 & 28,5 & 29,8 \\
& 28,5 & 28,7 & 30,1 \\
\hline Média & $\mathbf{2 7 , 4}$ & $\mathbf{2 8 , 5}$ & $\mathbf{2 9 , 9}$ \\
\hline Temperatura Externa & $\mathbf{1 6 , 4}$ & $\mathbf{1 9 , 3}$ & $\mathbf{2 1 , 4}$ \\
\hline
\end{tabular}

A norma regulamentadora correspondente à Ergonomia (NR 17), recomenda para atividades que merecem atenção constante um índice de temperatura efetiva entre $20^{\circ} \mathrm{C}$ a $23^{\circ} \mathrm{C}$. Com relação a determinação de condições de conforto, nota-se que, nenhuma das situações de temperatura interna nas cabines, atendeu a norma (Tabela 6). Somente o caminhão $C$ contém um sistema de ar condicionado, possibilitando que a temperatura permaneça ajustada de forma a proporcionar maior conforto.

Para atividade leve e com regime de trabalho contínuo como dos motoristas profissionais, o ambiente poderá atingir até $30^{\circ} \mathrm{C}$, sendo que, ao ultrapassar esse valor, o âmbito é considerado insalubre, segundo NR 15. De modo geral, nenhuma temperatura ultrapassou a margem de $30^{\circ} \mathrm{C}$, neste contexto, as temperaturas coletadas nos postos de trabalho, não são impostas em situações insalubres.

\subsubsection{Iluminação na cabine}

Os resultados da coleta de iluminação no interior das cabines em diferentes planos são demonstrados conforme a Tabela 7. As medições de iluminância foram realizadas em distintos horários ás 10, 12 e 16 horas, em condições de tempo ensolarado.

Tabela 7 - Medições da iluminância no posto de trabalho.

\begin{tabular}{cccc}
\hline Iluminação (Lux) & A & B & C \\
\hline \multirow{3}{*}{ Plano Frontal } & 800 & 755 & 338 \\
& 701 & 790 & 378 \\
& 762 & 791 & 390 \\
\hline Média & $\mathbf{7 5 4 , 3}$ & $\mathbf{7 7 8 , 7}$ & $\mathbf{3 6 8 , 6}$ \\
\hline \multirow{2}{*}{ Plano Lateral } & $\mathbf{7 3 0}$ & 988 & 714 \\
& 652 & 994 & 710 \\
\hline Média & 762 & 984 & 721 \\
\hline
\end{tabular}


Não há nenhuma norma específica para iluminação interna de caminhões, sendo necessária a adequação apropriada à natureza da atividade.

Os níveis mínimos de iluminamento a serem considerados nos locais de trabalho são valores de iluminância estabelecidos pela NBR 5413 - Iluminância de interiores [10]. Porém, esta norma também não indica a avaliação ergonômica em relação a iluminação em cabines de caminhões.

Como forma de investigação, o ambiente de trabalho no caminhão será ajustado na NBR 5413 na classe "A" como "Iluminação geral para áreas usadas interruptamente com tarefas visuais simples", com nível de iluminamento recomendado na faixa de 300 a 500 lux.

Analisando os valores encontrados, percebe-se que, os resultados estão acima dos parâmetros recomendados pela norma. Somente o caminhão C no plano frontal, se encontra na categoria estabelecida, isto porque, contém película protetora que inibiu a entrada de raios solares no plano de trabalho. Os demais caminhões não interagem de nenhum dispositivo de proteção.

Segundo Deva [11], a visão é um dos principais instrumentos de trabalho do profissional caminhoneiro, e quando estes não estão em condições saudáveis, não há como viajar por horas nas estradas.

A falta de uma norma que especifique a iluminação no interior da cabine de caminhões, merece estudo nessa área, para que possa ocorrer a melhoria de controle de iluminação, a fim de evitar acidentes ao longo da jornada de trabalho e futuros problemas de visão do condutor.

\subsection{Recomendações}

Com base nas avaliações, sugerem-se as seguintes recomendações:

- Implantar um programa de ginástica laboral para os motoristas, visando combater as dores no pescoço, coluna e desconforto lombar.

- Desenvolver uma Norma Regulamentadora (NR) específica para o setor.

- Elaborar propostas de promoção da saúde dos caminhoneiros e de atividades que visem ao diagnóstico e à prevenção de doenças.

\section{Conclusões}

A avaliação ergonômica através do método RULA, na população estudada apresentou nível 3, resultando em mudanças na postura dos motoristas.

A atividade exercida pelos motoristas profissionais propicia um quadro doloroso com dores no pescoço, lombar, e nádegas, pois é realizado na posição sentada durante a jornada de trabalho.

Os níveis de ruído estão acima de $60 \mathrm{~dB}$, portanto não apresentam um conforto acústico, segundo as condições impostas pela NR 17.

Em relação ao índice de temperatura efetiva, nenhuma das situações impostas no interior das cabines apresenta condições de conforto térmico normatizado pela NR 17.

Os valores de iluminação mostram-se bastante deficiente devida à falta de uma norma especifica para o interior da cabine de caminhões.

Recomenda-se para trabalhos futuros maiores debates e ações especificas no que diz a respeito à saúde física e mental desses protagonistas da logística do agronegócio do país. Visto que, ações em saúde e segurança para este público são raras, isoladas e ainda são tímidas no meio acadêmico e científico.

\section{ANALYSIS OF ERGONOMIC AND ENVIRONMENTAL CONDITIONS AT WORKERS: A CASE STUDY ON TRUCKS USED IN THE RURAL AND AGROINDUSTRIAL ENVIRONMENT}

ABSTRACT: The transportation of cargo that moves the economy of Brazil is conducted with sovereignty through the road system, raising the driver of a truck to a profession of enormous importance for the various economic segments, especially for agribusiness. The objective of the present study was to evaluate the ergonomic and environmental conditions of truck drivers' positions that work in agribusiness related activities. The case study was carried out in the Western Frontier with professional drivers who perform tasks in rural and agroindustrial environments. For postural analysis, we performed filming and the generation of 240 sequential photos as a reference of the activity cycle. Through the software Ergolândia 6.0 the images were analyzed by the RULA method, which resulted in the need for intervention in the drivers posture. Through the Bipolar questionnaire it was observed that the activity performed by the drivers presents a painful picture. Regarding the occupational noise and temperature analyzes, no parameter presented comfort to the individuals according to the normalization of NR 17. The 
illumination values proved to be quite deficient due to the lack of a specific standard for the interior of the truck cab.

Keywords: Agribusiness. Transport. Truck. Occupational Health.

\section{Referências}

[1] LOPES, Y. C. O transporte de produtos agrícolas e a otimização de seus resultados. 2015. 47p. Trabalho de Conclusão (Ensino Superior de Assis) - Instituto Municipal de Ensino Superior de Assis. Assis - SP. 2015.

[2] FILHO, J. V. A logística do escoamento da safra brasileira. 2016. 3p. Universidade de São Paulo. São Paulo - SP. 2016.

[3] RIBEIRO, C. L.; NUNES J. D. Caracterização da saúde dos condutores de veículos pesados e perigosos que trafegam em rodovia federal no estado de Sergipe. 2016. 39p. Trabalho de Conclusão (Enfermagem) - Universidade Tiradentes. Aracaju - SE. 2016.

[4] LIMA, K. C.; SIQUEIRA, B. B.; NETO, A. F.; MARINHO, G. V. Análise preliminar do risco na atividade de motoristas de ônibus em João Pessoa - PB. In: XXXVI ENCONTRO NACIONAL DE ENGENHARIA DE PRODUÇÃO, 2016, João Pessoa. Anais. João Pessoa/PB. p. 1-10. 2016.

[5] ALCARÁS, P. A.; MENEZES, G. A.; JUDAI, M. A. Avaliação audiológica em caminhoneiros. Revista Colloq Vitae. v.8, n.2, 2016. 10p.

[6] CARS. A importância de conduzir um caminhão com a postura correta. 2018. Disponível em: < http://feiraocars.com.br/noticia/saiba-a-importancia-emconduzir-o-caminhao-com-a-postura-correta>. Acesso em: 31 Out. 2018.

[7] POSSEBOM, G.; MOREIRA, A. R.; CARPES, D. P.; FRANCETTO, T. R.; ZART, B. C.; ALONÇO, P. A.; ALONÇO, A. S. Avaliação ergonômica em um viveiro florestal de Santa Maria - RS. Revista Tecno-lógica. v.21, n.1, 2016. 7p.

[8\} ABNT. ASSOCIAÇÃO BRASILEIRA DE NORMAS TÉCNICAS. NORMA REGULAMENTADORA (NR 17): Ergonomia. Portaria SSMT. 1990. Disponível em: <http://www.mte.gov.br/legislacao/.> Acesso em: 11 Out. 2018.

[9] ABNT. ASSOCIAÇÃO BRASILEIRA DE NORMAS TÉCNICAS. NORMA REGULAMENTADORA (NR 15): Atividades e Operações Insalubres. Portaria SSMT. 1990. Disponível em: 〈http://www.mte.gov.br/legislacao/>. Acesso em 11 Out. de 2018.

[10] ABNT. ASSOCIAÇÃO BRASILEIRA DE NORMAS TÉCNICAS. NBR 5413: Iluminância de interiores. Rio de Janeiro. 1992.

[11] DEVA, IVECO. Caminhoneiro: cuidados ao dirigir em dias de sol. 2016. Disponível em: < http://blog.deva.com.br/caminhoneiro-4-cuidados-ao-dirigir-emdias-de-sol/>. Acesso em: 21 Abri. 2018. 